\title{
Stimulus-dependent suppression of intrinsic variability in recurrent neural networks
}

\author{
Kanaka Rajan ${ }^{*}$, Laurence F Abbott ${ }^{2}$, Haim Sompolinsky ${ }^{3}$ \\ From Nineteenth Annual Computational Neuroscience Meeting: CNS*2010 \\ San Antonio, TX, USA. 24-30 July 2010
}

Trial-to-trial variability is an essential feature of neural responses and is likely to arise from a complex interaction between stimulus-evoked activity and ongoing spontaneous neural activity in the central nervous system. Response variability is often treated as random noise generated either by an external source like another brain area, or by stochastic processes within the circuit. A considerable amount of variability can also arise from the same circuitry and intrinsic network dynamics that generate responses to a stimulus. Indeed ongoing neural activity in the central nervous system is comparable in magnitude and complexity to activity evoked by sensory stimuli [1,2].

How can we distinguish between external and internal sources of neuronal variability? We ask whether internal and external sources of variability depend on stimulus features in different ways, giving them distinct experimental signatures and functional interpretations. How are stimulus-evoked responses faithfully extracted from complex background activity to identify real features of the external world?

We use a neural network model that generates highly irregular and chaotic patterns of activity in the absence of stochastic input. On the basis of numerical simulations and mean-field calculations [1], we find a phase transition between two basic dynamic behaviors: a periodic state where the network is locked in phase and frequency to the external stimulus, and a chaotic state where neurons behave as noisy oscillators with only partial entrainment to the stimulus (Figure 1). We construct phase diagrams showing how these dynamics depend on the strength and frequency of the external input, the strength of the connectivity, and the residual imbalance between excitation and inhibition. We argue

\footnotetext{
* Correspondence: krajan@princeton.edu

${ }^{1}$ Lewis-Sigler Institute for Integrative Genomics, Princeton University, Princeton, NJ, USA
}

that sensory-evoked responses can actively suppress ongoing intrinsically generated fluctuations. This provides a theoretical basis and potential mechanism for the experimental observation that intrinsic neuronal variability is reduced by the presence of a stimulus [1-3].

We also show that the nonlinear interaction between the relatively slow intrinsic fluctuations and external stimulus results in a non-monotonic frequency dependence of this suppression. Consequently, measures of trial-to-trial variability of neural responses can be more

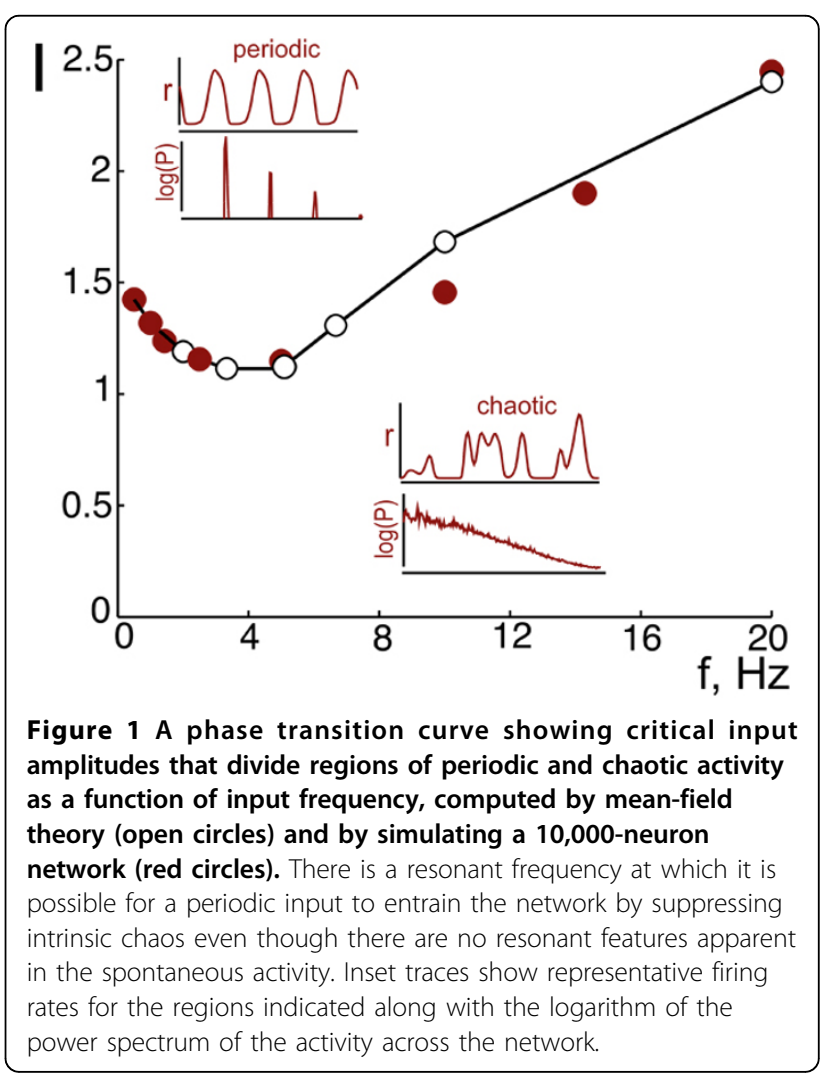


sensitive to the amplitude and frequency of the stimulus, compared to the mean responses that are typically the focus of electrophysiological studies.

\section{Author details}

${ }^{1}$ Lewis-Sigler Institute for Integrative Genomics, Princeton University,

Princeton, NJ, USA. ²Department of Neuroscience, Columbia University, New York, NY, USA. ${ }^{3}$ Racah Institute of Physics, Interdisciplinary Center for Neural Computation, Hebrew University, Israel.

Published: 20 July 2010

\section{References}

1. Please find detailed methodology as well as relevant references in the supplement to this abstract..

2. Arieli A, Sterkin A, Grinvald A, Aertsen A: Dynamics of ongoing activity: explanation of the large variability in evoked cortical responses. Science 1996, 273:1868-1871.

3. Churchland MM, Yu BM, Cunningham JP, Sugrue LP, Cohen MR,

Corrado GS, Newsome WT, Clark AM, Hosseini P, Scott BB, et al: Stimulus onset quenches neural variability: a widespread cortical phenomenon. Nature Neurosci 2009.

doi:10.1186/1471-2202-11-S1-017

Cite this article as: Rajan et al:: Stimulus-dependent suppression of intrinsic variability in recurrent neural networks. BMC Neuroscience 2010 11(Suppl 1):O17.

\section{Submit your next manuscript to BioMed Central} and take full advantage of:

- Convenient online submission

- Thorough peer review

- No space constraints or color figure charges

- Immediate publication on acceptance

- Inclusion in PubMed, CAS, Scopus and Google Scholar

- Research which is freely available for redistribution

Submit your manuscript at www.biomedcentral.com/submit 